\title{
ENTRE A CRIAÇÃO E A OBEDIÊNCIA: A JUDICIALIZAÇÃO INVADE A ESCOLA
}

\author{
Luiz Antonio Saléh Amado ${ }^{1}$ \\ Universidade do Estado do Rio de Janeiro, Rio de Janeiro-RJ, Brasil
}

\begin{abstract}
RESUMO. O artigo pretende problematizar as relações e as práticas vinculadas à escola, as quais têm sido marcadas por uma lógica judicializante. Para isso traz exemplos de casos recentes, em que nos deparamos com discursos que demandam mais controle, mais vigilância e, nesta lógica, mais punição. Sob o pretexto de defender a educação de qualidade, os códigos de conduta e o respeito ao professor, as situações descritas exemplificam muitas práticas, na sociedade e nas escolas, que contribuem para alimentar a racionalidade que considera 0 poder judiciário a instância por excelência onde as dificuldades e os conflitos escolares devem ser resolvidos. $O$ texto alerta para a necessidade de não encararmos os problemas escolares como ameaça à existência da própria escola, mas analisarmos os processos instituídos e problematizarmos as práticas que buscam prevenir condutas desviantes através de discursos moralizantes e de métodos punitivos. Neste sentido, defende a construção de alternativas para estes problemas através da participação dos sujeitos que habitam a escola, pois a potencialização de professores, alunos e demais agentes institucionais possibilitará que as escolas se transformem em espaços para a ampliação dos modos de existência.
\end{abstract}

Palavras-chave: Educação; justiça; controle social.

\section{BETWEEN THE CREATIVITY AND THE OBEDIENCE: THE JUDICIALIZATION INVADES THE SCHOOL}

\begin{abstract}
This article intends to discuss the school relationships and practices that have been marked by a judicial logic. Getting examples of recent cases, it shows discourses that require more control, more vigilance and sometimes more punishment. Under the pretext of defending the quality education, the codes of conduct and the respect for the teacher, the situations described exemplify practices that multiply in the society and in the schools, which contribute to feed the rationality that considers the judiciary instance par excellence where difficulties and school conflicts must be solved. The text indicates the necessity of facing the school problems not as a threat to the existence of the school itself, but as analyzers of the instituted processes and also problematizing the practices that seek to prevent deviant behavior by moralizing discourses and punitive methods. In this sense, it defends the construction of alternatives to these problems through the participation of the subjects that inhabit the school, because the potentiation of teachers, students and other institutional agents will allow the modes of existence expansion inside the school.
\end{abstract}

Keywords: Education; justice; social control.

\section{ENTRE LA CREATIVIDAD Y LA OBEDIENCIA: LA JUDICIALIZACIÓN INVADE LA ESCUELA}

RESUMEN. El artículo se propone discutir las relaciones y prácticas relacionadas con la escuela que han sido marcadas por una lógica judicializante. Para ello, trae ejemplos de casos recientes, a partir de los cuales encontramos discursos que requieren más control, más vigilancia, siendo así, más castigo. Bajo el pretexto de defender la educación de calidad, los códigos de conducta y el respeto al maestro, las situaciones descriptas ejemplifican las prácticas que se multiplican en la sociedad y en las escuelas, que contribuyen para alimentar la racionalidad que considera el poder judiciario la instancia por excelencia donde las dificultades y los conflictos escolares deben ser resueltos. El texto llama la atención para la necesidad de afrontar los problemas escolares no como una amenaza para la existencia de la propia escuela, sino como analizadores de los procedimientos instituidos y también de problematizar las prácticas que buscan prevenir conductas desviantes a través de discursos moralizantes y de métodos punitivos. En este sentido, defiende la construcción de alternativas a estos

1 Endereço para correspondências: Rua Alice, 194/803, Laranjeiras, CEP 22.241-020 - Rio de Janeiro-RJ, Brasil. Email: saleh.amado@gmail.com. 
problemas a través de la participación de los sujetos que habitan la escuela, pues la potenciación de profesores, estudiantes y demás actores institucionales permitirá que la escuela pueda transformarse en espacios para la expansión de los modos de existencia.

Palabras-clave: Educación; justicia; control social.

Por que, para ensinar alguma coisa a alguém, se deve punir e recompensar?

Foucault (2003, p. 121)

Uma imagem já bastante conhecida dos professores, e mesmo dos usuários das redes sociais, é aquela que compara duas salas de aula, uma do início do século XX e uma do início do século XXI. Ao se destacar a evidente semelhança entre as duas, objetiva-se criticar a lentidão da educação em acompanhar os avanços tecnológicos, sobretudo os ocorridos nos últimos trinta anos. No bojo destas críticas identificam-se também outras, direcionadas ao modo como o professor lida com as questões escolares atuais, em função de suas próprias dificuldades em acompanhar as transformações sociais contemporâneas, além da rigidez disciplinar que parece acompanhá-lo ainda hoje.

Além dos desdobramentos que essa imagem pode provocar, percebemos que os estudantes vão desenvolvendo outras formas de relação, outros modos de frequentar a escola; mas a presença das tecnologias eletrônicas nos espaços escolares reforça a preocupação dos professores, pesquisadores e educadores de forma geral com o comportamento dos estudantes, que consideram inadequado. A queixa mais comum se refere à perda da autoridade dos professores. Atualmente, sobretudo nos meios urbanos, a multiplicação de exemplos nesse sentido vão desde a desatenção provocada pelo uso de dispositivos eletrônicos de comunicação em sala de aula principalmente os aparelhos de telefone celular até as situações de violência protagonizadas pelos alunos contra os professores. Nesse conjunto de queixas também se destacam aquelas sobre o suposto descaso de alguns pais que não frequentam as reuniões convocadas pela escola, o que se sugere estar contribuindo para o comportamento descompromissado e desrespeitoso dos alunos.

Nos últimos anos os professores têm demonstrado dificuldade em lidar com as transformações das subjetividades dos jovens contemporâneos, como se pode constatar pelas conversas entre esses profissionais, seja em encontros casuais nas salas de professores das escolas, seja em encontros formais (seminários, congressos, etc.) dedicados aos temas deste campo de estudo e de trabalho. As tensões vividas na relação entre docentes e discentes, geralmente interpretadas como falta de respeito, indisciplina ou rebeldia, já não são resolvidas mediante o apelo aos instrumentos simples, descritos por Foucault (1989), outrora responsáveis pelo sucesso do poder disciplinar: "o olhar hierárquico, a sanção normalizadora e sua combinação num procedimento que the é específico, o exame" (p. 153).

Conforme já alertara Deleuze (1992) no final do século $X X$, ao apontar as forças que lentamente vão se instaurando e deslocando a disciplina do centro da cena, vivemos uma crise generalizada dos meios de confinamento - como a prisão, o hospital, a fábrica, a família e a escola - os quais as tentativas de reforma não serão capazes de evitar. Ainda segundo Deleuze, as disciplinas que funcionavam nos espaços de confinamento, na duração de um sistema fechado, são acopladas às formas ultrarrápidas de controle ao ar livre ou até substituídas por elas.

Alguns estudos (Heckert \& Rocha 2012, Sibilia, 2012) têm chamado a atenção para as dificuldades que a escola vem enfrentando diante das transformações sociais contemporâneas. Neste processo observa-se que a escola já não consegue cumprir suas funções disciplinares como em outros momentos, o que resulta na descontinuidade entre família, escola, fábrica, por exemplo, contrariando uma das características mais marcantes da sociedade disciplinar. As subjetividades que eram produzidas no âmbito destes dispositivos disciplinares - cujo funcionamento devia se dar articuladamente, alimentando e reforçando os modos de ser e estar ali construídos - passam a sofrer influência cada vez maior de outros meios, mais especificamente das novas tecnologias eletrônicas de comunicação. Essa configuração social contemporânea tem colocado desafios importantes para a escola, mas infelizmente as respostas têm sido pouco eficientes. 
A proposta deste artigo é problematizar as relações e as práticas vinculadas à escola que têm sido marcadas pela lógica judicializante e, neste sentido, traz exemplos de casos recentes, em que nos deparamos com discursos que demandam mais controle, mais vigilância e, nessa lógica, mais punição. Sob o pretexto de defender a educação de qualidade, os códigos de conduta e o respeito ao professor, as situações analisadoras que serão apresentadas neste texto contribuem para alimentar a racionalidade que considera o poder judiciário a instância por excelência de resolução das dificuldades e conflitos surgidos na escola. Em se tratando de situações analisadoras, é preciso considerar que, de acordo com a Análise Institucional, analisadores são os dispositivos ou acontecimentos que favorecem o aparecimento de movimentos diferentes dos que funcionam habitualmente, permitindo colocar em discussão a maneira como as relações e as práticas institucionais se organizam numa dada situação.

\section{CONFINADOS E DESCONECTADOS}

Se a escola, pelas técnicas de poder centradas no corpo individual, constituiu-se como um dos espaços responsáveis pelo disciplinamento dos corpos, não podemos ignorar que outros mecanismos de poder também atuavam no âmbito escolar. Segundo Foucault (1999), desde o final do século XVIII uma nova tecnologia de poder, a tecnologia regulamentadora da vida, junta-se à tecnologia disciplinar do corpo ou a ela se sobrepõe. Enquanto esta última produz a individualização, está centrada no corpo e o manipula com vistas a torná-lo útil e dócil, aquela se volta para a população, com o objetivo de controlar a série de eventos casuais que "podem ocorrer numa massa viva; uma tecnologia que procura controlar (eventualmente modificar) a probabilidade desses eventos, em todo caso em compensar seus efeitos" (p. 297).

Por outro lado, Foucault (1999) afirma que os mecanismos disciplinares e os regulamentadores não estão no mesmo nível e por isso são capazes de se articular. Citando como exemplo a cidade operária do século XIX, o autor exemplifica esta articulação mostrando que a própria disposição espacial da cidade torna os indivíduos visíveis e normaliza suas condutas. Prosseguindo, o autor afirma que há uma série de mecanismos regulamentadores que incidem sobre a população enquanto tal $e$ a induzem a determinados comportamentos. Estes comportamentos, que se deseja serem frequentes na população, estão ligados à segurança, à saúde, enfim, aos cuidados. São, segundo Foucault, formas de pressão “... que a própria organização da cidade exerce sobre a sexualidade, portanto sobre a procriação; as pressões que se exercem sobre a higiene das famílias; os cuidados dispensados às crianças; a escolaridade, etc." (1999, p. 300).

Assim, a escola funciona não apenas como espaço de disciplinamento dos corpos, mas também como regulamentação e como espaço de uma biopolítica que pretende gerenciar a vida. Essa articulação entre mecanismos de poder diferentes, com suportes e objetivos distintos, também é destacada por autores que têm se dedicado à análise das transformações sociais contemporâneas e seus efeitos sobre a produção das subjetividades dos que transitam pela escola.

Segundo Machado (1999), no Brasil também vivemos as crises dos espaços fechados (escola, prisão, etc.), mas temos uma forma peculiar de lidar com as tecnologias de poder, pois "... misturamos de uma forma específica exercícios de poder que evidenciam soberania, disciplina e gerência da vida" (p. 217). Na visão de Heckert e Rocha (2012), “... a gestão dos riscos e dos perigos parece funcionar pela conexão de dispositivos mistos - disciplinar e de controle - de modo a efetuar de forma generalizada e totalizante a inclusão diferencial de todos" (p. 88), o que pode indicar certa utilização estratégica da escola como espaço de controle e de governo da vida. As autoras destacam alguns exemplos de processos que atravessam a escola atualmente, demarcam campos problemáticos, definem comportamentos patologizados e, em outros casos, promovem a criminalização de condutas. Nesse sentido, afirmam:

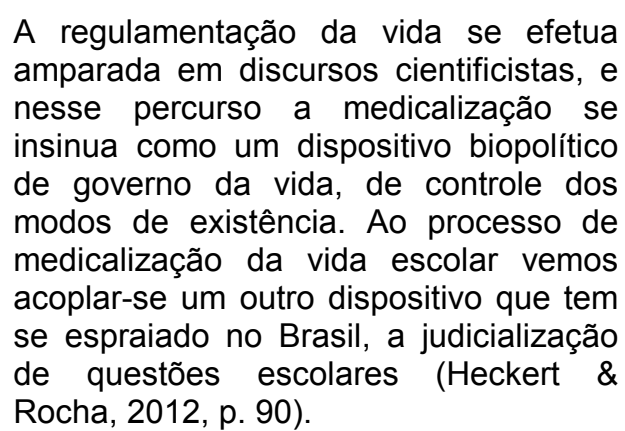

Mais à frente, quando discutir alguns casos que concernem às tensões recentemente surgidas nas 
escolas, retornarei à ideia de judicialização. Por ora, basta afirmar, junto com Heckert e Rocha (2012), que certos comportamentos que se apresentam como enfrentamentos à ordem instituída, em vez de serem encarados como analisadores dos modos de construir as relações na escola, costumam ser interpretados como problemas médicos, jurídicos ou, simplesmente, como casos de polícia.

Voltando a atenção especificamente para a explosão da tecnologia eletrônica de comunicação nos últimos anos, Sibilia (2012) destaca as características atuais das relações construídas entre os jovens, entre eles e o conhecimento, ou melhor, a informação, e entre esses mesmos jovens e as estruturas disciplinares tradicionais, cuja materialização mais fiel é a escola. Com o olhar aguçado para os efeitos das novas tecnologias sobre a escola, a autora afirma que as instituições disciplinares típicas dos séculos XIX e XX talvez hoje prescindam da vigilância hierárquica, do confinamento com controle do tempo e das sanções normalizadoras como técnicas para a docilização e a utilização dos corpos. O controle parece ser mais eficiente se se consegue unir os corpos aos circuitos integrados do universo atual, como diz a autora. Nesse ponto ela chama a atenção para as transformações ocorridas nas subjetividades dos alunos, destacando o contraste entre as formas de comunicação dos jovens contemporâneos, os modos de organização de suas relações e o instrumental antiquado utilizado pela escola. Segundo Sibilia, estar conectado é algo a que os sujeitos se entregam; e particularmente no caso das crianças e dos jovens, afirma:

As crianças e os mais jovens parecem apreciá-lo especialmente, motivo pelo qual se dedicam a tais atividades a todo momento e em qualquer lugar. Muitas vezes o fazem, inclusive, driblando as eventuais proibições das hierarquias escolares; aliás, costumam recorrer a essas conexões para sobreviver à chatice que implica ter que passar boa parte de seus dias encerrados nas salas de aula, mais desesperadamente desconectados que disciplinadamente confinados (Sibilia, 2012, p. 177).

\section{TRÊS CASOS ANALISADORES}

A seguir apresentarei três casos recentes envolvendo a escola, com o objetivo de colocar em análise as relações que estão sendo construídas dentro e fora dela. O primeiro deles - pautar as manifestações e enquadrar a escola - refere-se à intenção dos meios de comunicação de regular as palavras de ordem e os cartazes reivindicativos que surgiram nas manifestações iniciadas no mês de junho de 2013, em mais uma tentativa de regulação da vida. Aqui cabe a observação de que a partir de junho desse ano inúmeras manifestações ocorreram em várias capitais do país. Estas manifestações tinham como reivindicação principal a redução do valor das passagens de ônibus, mas rapidamente extrapolaram este tema e, variando os motivos e os participantes envolvidos, continuaram acontecendo por alguns meses. Retomando o assunto, apesar de o caso em questão se dirigir às manifestações portanto, a espaços fora da escola -, visa interferir diretamente no que acontece dentro dela. O segundo caso - os celulares vão à escola -, diz respeito à Lei Estadual que proibiu o uso de celulares nas escolas do Estado do Rio de Janeiro e pode exemplificar, juntamente com o caso seguinte, o processo de judicialização das questões escolares atualmente em curso. Por fim, o terceiro caso, a escola entre a criação e a obediência, trata do projeto de lei que propõe acrescentar ao Estatuto da Criança e do Adolescente (ECA) um artigo que exija dos jovens o respeito à autoridade intelectual e moral dos docentes. Além de configurar um exemplo a mais do tratamento judicial conferido a certas questões da escola, tal artigo permitiria problematizar as condições que nos possibilitam lidar com determinados problemas escolares do modo como o fazemos hoje e, ainda, colocar em análise seus efeitos.

\section{Pautar as manifestações, enquadrar a escola}

Antes de descrever este primeiro caso vale a pena situá-lo no conjunto de tentativas da mídia de assumir o comando da formulação de reivindicações durante as manifestações que varreram as principais capitais do país em junho de 2013. Nessa ocasião assistimos a inúmeros exemplos de como a mídia é ávida por controlar corações e mentes. Felizmente as manifestações também serviram para mostrar quanto o sucesso destas investidas tem se mostrado difícil de ser alcançado, pois hoje em dia torna-se arriscado e quase impossível manter uma única versão para os fatos, quer pela ampla circulação de informações via redes sociais, em 
tempo real, quer pela estrutura atual da própria mídia televisiva, na qual as TVs a cabo oferecem vasto cardápio de programas jornalísticos, segmentados pelo perfil do público ao qual se destinam e, consequentemente, com variadas abordagens para um mesmo acontecimento.

Nas primeiras manifestações de junho certos programas do jornalismo televisivo repetiam compulsivamente estratégias buscando produzir a versão oficial para o que acontecia naquele momento; mas com surpresa assistimos a inúmeras imagens ao vivo por meio das quais a contradição se explicitou com o programa ainda no ar. Apesar disso, como afirmou Deleuze (1992) ao analisar a emergência das sociedades de controle ante as sociedades disciplinares, "os anéis de uma serpente são ainda mais complicados que os buracos de uma toupeira" (p. 226). Assim, os meios de comunicação ágil e rapidamente buscaram estratégias alternativas com o objetivo de manter-se à frente das manifestações. Neste sentido, a todo custo tentavam pautar as reivindicações dos manifestantes, interpretando seus movimentos de forma a adiantar-se a seus desejos.

Laurindo Filho (2013), apontando o vaivém da mídia, destaca as mudanças na cobertura das manifestações de rua que aconteceram pelo Brasil em junho de 2013. Citando especificamente a Rede Globo, o autor afirma que a cobertura inicial, francamente desfavorável às manifestações, acabou sendo alterada em função da força que as manifestações adquiriram, juntando às reivindicações dos preços das passagens dos ônibus a indignação contra a violência policial. Essa estratégia não é nova, pois como ele lembra, em 1984 a emissora adotara comportamento semelhante, quando tentou esconder o máximo possível o movimento pelas eleições diretas.

Como conter (prever) essas reações hoje em dia, diante das amplas e variadas facilidades de comunicação instantânea?

As tentativas de pautar as reivindicações e de tomar as rédeas das manifestações ficavam claras quando mais uma vez, de acordo com Laurindo Filho (2013), as emissoras tentaram instrumentalizar o movimento, colocando "suas bandeiras nas mãos dos participantes, estimulando, por exemplo, os gritos contra a aprovação da PEC-37 (um enigma para a maioria da população) e um difuso combate à corrupção" (p. 7).
Mas vamos ao caso em questão. Aproveitando o feriado de Sete de Setembro deste ano, vários grupos se pronunciaram previamente, convocando manifestações em diversas cidades do país. Prontamente, na semana anterior ao feriado, uma rádio de notícias de abrangência nacional (CBN, 2013) sugeriu a confecção de cartazes que poderiam ser utilizados nas manifestações previstas para o dia da Independência. Estas sugestões foram feitas numa coluna semanal mantida pela rádio, destinada a debater assuntos relacionados à educação.

Demonstrando clara vinculação com propostas conteudistas, os apresentadores sugeriram, por exemplo, alguns cartazes alusivos à organização curricular, com base em argumentos que destacavam as deficiências de leitura e de matemática apontadas nas avaliações nacionais e internacionais, largamente divulgadas. De acordo com a proposta da rádio, estes cartazes defendiam que, ao completar nove anos, os alunos deveriam, pelo menos, ter lido um livro de 200 páginas e ser capazes de realizar as quatro operações com números de 6 algarismos.

Numa outra categoria de cartazes os apresentadores defendiam o "ensino integral já, com sete horas diárias na educação básica". Mais uma vez os argumentos são fundamentais para entender a lógica que sustenta tal sugestão de reivindicação. Segundo afirmaram, a educação integral "já está começando no Brasil, mas com viés que não é legal". O viés reprovado pelos apresentadores é descrito como certa tendência em "colocar o aluno para pintar muro, bater tambor"; mas imediatamente se apressaram em ressaltar que ensinar artes e esportes é ótimo, mas "é preciso ter foco nas habilidades cognitivas; é preciso focar naquilo que faz com que depois ele [o aluno] seja um cidadão que não seja enganado facilmente".

Havia também a preocupação de se mudar a cultura da escola, como ficou claro na proposição dos cartazes alusivos ao controle de frequência, pois, segundo os apresentadores do programa da rádio, o Brasil começou muito tarde a matricular todos na escola, portanto, "não temos uma cultura de frequentar a escola nem de pontualidade; por isso, ainda é algo que não é levado a sério nem pelos pais, nem pelos alunos, nem pelos professores". O controle eletrônico de presença de alunos e professores foi, então, o cartaz proposto, com a ressalva de 
que deveria ser assim pelo menos até que se instituísse a cultura de frequentar a escola diariamente.

Os meios de comunicação têm se caracterizado pela pouca preocupação com a coerência. As manifestações de junho tiveram como disparador os movimentos em torno do passe livre ou, de acordo com um slogan que se popularizou rapidamente, "por uma vida sem catracas"; porém isso parece não ter sido considerado pela rádio, pois, em franca sintonia com os processos atuais de controle social baseados na tecnologia eletrônica, um dos cartazes propostos pela emissora solicitava nada mais nada menos do que catracas para as escolas. Além da incoerência ativamente reproduzida nesses meios comunicacionais, para um programa destinado a debater assuntos de interesse da educação, pode-se dizer que o desconhecimento acerca das discussões e das iniciativas em torno do ensino integral e do currículo integrado é alguma coisa, no mínimo, reprovável. Não obstante, percebe-se que as tentativas de colocar nas bocas e mãos dos manifestantes as palavras de ordem previamente definidas pela rádio seguiram a mesma linha dos meios de comunicação citados acima, visando instrumentalizar as manifestações e domesticar um movimento de enfrentamento muito mais denso do que a versão proposta pela rádio. Por fim, é preciso destacar a aproximação de propostas como a do controle do ponto com mecanismos de regulação, disciplinamento e punição, que nada contribuem para colocarmos em análise a educação instituída - suas práticas de reprodução do fracasso, do tédio, da falta de sentido.

\section{Os celulares vão à escola}

O aumento exponencial do uso de aparelhos eletrônicos de comunicação afetou o comportamento de todos - adultos e crianças. Hoje os telefones celulares são praticamente extensões dos corpos dos sujeitos. Já não é mais novidade ouvirmos as pessoas, em especial os jovens, declararem não conseguir viver sem seus aparelhos celulares.

No caso específico da invasão da escola pelos telefones celulares, a preocupação com o desempenho (e o comportamento) dos alunos chegou a tal ponto, que em 11 de abril de 2008 foi sancionada no Rio de Janeiro a Lei $n^{\circ} 5222$, que proibia o uso destes aparelhos nas escolas do Estado. No ano seguinte esta lei foi modificada por outra, a Lei $n^{\circ} 5453$, de 26 de maio de 2009, que ampliava a proibição para "telefones celulares, walkmans, diskmans, Ipods, MP3, MP4, fones de ouvido e/ou bluetooth, game boy, agendas eletrônicas e máquinas fotográficas." O uso destes equipamentos ficava proibido nas salas de aulas, nas bibliotecas e outros espaços de estudo, tanto para alunos quanto para professores da rede pública estadual de ensino. A única exceção era a utilização para fins pedagógicos, caso em que o estabelecimento de ensino deveria expedir prévia autorização.

Não é difícil perceber que se trata de mais uma lei que não conseguiu produzir os efeitos desejados. Neste caso, as reações produzidas variam de acordo com a situação (se nas aulas regulares ou se durante as avaliações) e com os professores (se mais ou menos rígidos). Percebemos, ao final, o movimento de alguns tentando encontrar outras formas de convivência com estes aparelhos em sala de aula, porém, com maior frequência, deparamo-nos com a dificuldade de colocar em análise as relações instituídas no âmbito escolar.

\section{A escola entre a criação e a obediência}

O terceiro e último caso trata de um projeto de lei curioso, pois visa garantir o respeito dos estudantes para com os professores. O projeto, PL 267/11, da deputada Cida Borghetti, tramita em caráter conclusivo, já tendo sido aprovado na Comissão de Seguridade Social e Família. No momento em que este artigo estava sendo escrito - outubro de 2013 - o projeto era analisado na Comissão de Educação da Câmara dos Deputados, de onde deveria seguir para a Comissão de Constituição e Justiça e de Cidadania.

A proposta contida no projeto prevê a alteração do Estatuto da Criança e do Adolescente (ECA) com o acréscimo do seguinte artigo: "Na condição de estudante, é dever da criança e do adolescente observar os códigos de ética e de conduta da instituição de ensino a que estiver vinculado, assim como respeitar a autoridade intelectual e moral de seus docentes" (PL 267/11, 2011).

Como se observa a partir da leitura do projeto de lei, bem como das justificativas que o acompanham, não há definição clara do que será considerado descumprimento da referida lei, nem há caracterização mais precisa do que 
poderá vir a ser julgado desrespeito à autoridade dos professores. Não obstante, na visão da autora da proposta, o poder judiciário parece ser a instância mais adequada para a solução deste tipo de situação, como se pode depreender da leitura do parágrafo único, que prevê sanções no caso de desobediência ao que está disposto na lei: "O descumprimento do disposto no caput sujeitará a criança ou adolescente à suspensão por prazo determinado pela instituição de ensino e, na hipótese de reincidência grave, ao seu encaminhamento à autoridade judiciária competente" (PL 267/11, 2011).

A preocupação com os comportamentos desviantes na escola não é algo novo. O que surpreende é a articulação das estratégias disciplinares de controle com as tentativas de regular a vida, resultando na produção de práticas cujas expressões mais marcantes têm sido a judicialização. De acordo novamente com Heckert e Rocha (2012), é possível perceber como tem funcionado a utilização, pela escola, de estratégias que criminalizam ou remetem ao campo jurídico temas das mais variadas naturezas:

\begin{abstract}
Esta judicialização tem se caracterizado pela expansão da ação da justiça no território da escola, com o aparato jurídico sendo acionado para intervir em conflitos que emergem no chão da escola e/ou para esclarecer dúvidas, muito mais quanto aos deveres não cumpridos do que com relação aos direitos sociais não garantidos. A lógica judicial passa a permear o cotidiano escolar, ofertada e requisitada, principalmente, para manter a ordem. Utilizando-se de ameaças de punição, intensifica-se a criminalização de ações que interrogam as práticas instituídas, forjando-se políticas do medo e do controle do suposto risco social (Heckert \& Rocha, p. 90).
\end{abstract}

As justificativas alegadas pela autora do referido projeto de lei nos fornecem indícios de como as lógicas disciplinares e regulamentadoras podem se articular em ações que remetem ao campo jurídico assuntos que poderiam ser tratados através de outras abordagens, sobretudo comportamentos alinhados ao conjunto de ações que questionam as práticas instituídas. Embora a escola comporte movimentos instituintes, ações como estas legitimam e realimentam determinado modo de funcionamento escolar, apoiado na racionalidade jurídica. Não custa lembrar a afirmação de Foucault (2003) de que "o sistema escolar é também inteiramente baseado em uma espécie de poder judiciário. A todo momento se pune e se recompensa, se avalia, se classifica, se diz quem é o melhor, quem é o pior" (p. 120).

Logo no início da justificativa ao projeto de lei a autora promove a correspondência indevida entre indisciplina e violência, ao lamentar que a "indisciplina em sala de aula tornou-se algo rotineiro" (PL 267/11, 2011), acrescentando que os casos de violência contra professores vêm aumentando assustadoramente. Ora, se os casos de violência contra professores (ou qualquer outra pessoa) não podem ser negligenciados, especialmente quando atingem limites críticos, colocando em risco a vida, é de perguntar se uma lei que exige o respeito aos mestres resolve o problema.

Prosseguindo 0 arrazoado com 0 qual pretende justificar a alteração do Estatuto, a deputada destaca que o ECA garante inúmeros direitos aos jovens no que se refere à educação e estabelece as obrigações do Estado e da sociedade, porém não prevê, segundo ela, dispositivos que disciplinem as obrigações que os estudantes devem ter para com seus mestres. Com base nisso, conclui:
Assim sendo, a proposição determina ser obrigação da criança e do adolescente estudante a observância dos códigos de ética e de conduta da instituição de ensino a que estiver vinculado, bem como o respeito à autoridade intelectual e moral do professor (PL 267/11, 2011, n. p.).

Felizmente, os discursos que pretendem reforçar a necessidade de mais leis, de mais justiça e de mais regulações não são únicos. Outras vozes têm defendido práticas que tomem os comportamentos considerados desviantes, os casos de rebeldia ou de indisciplina, as formas assumidas pelas relações forjadas na escola, como analisadores dos processos instituídos nestes espaços. São práticas que não se restringem à busca das causas orgânicas, psíquicas ou sociais desses comportamentos, tampouco se perdem na elaboração infindável de regulamentos cada vez mais próximos da legislação penal; mas, assumindo uma posição ético-política francamente distinta, pretendem indagar quais foram as condições que 
possibilitaram o estabelecimento de relações entre a escola e os estudantes, destes entre si ou com o conhecimento, do modo como essas relações são observadas atualmente. Tais práticas não se eximem de enfrentar a situação complexa com a qual a escola se depara na atualidade, mas colocam em análise os dispositivos que sustentam as propostas judicializantes para a solução dos conflitos e das dificuldades envolvendo a escola. Ao encararem os acontecimentos como analisadores do instituído na escola, essas práticas afirmam seu compromisso não com a obediência, mas com a criação de outros modos de ser e estar no mundo.

\section{CONSIDERAÇÕES FINAIS}

De fato, alguns exemplos encontrados nas situações descritas mostram a preocupação com os resultados da educação, mas também com a integridade moral e física dos professores, além de pretenderem evitar os comportamentos desviantes, o que, certamente, não é prerrogativa dos tempos atuais; mas mesmo diante de mecanismos de controle mais sofisticados, como os descritos por Deleuze (1992) ao se referir às sociedades de controle, presenciamos um movimento muito claro de delegar à justiça assuntos que costumavam ser tratados em outras instâncias, sobretudo os processos cotidianos pertencentes às relações estabelecidas no interior ou no entorno das escolas.

Seria o caso de nos perguntarmos, então, quais os caminhos que levam a sociedade a recorrer às leis - proibição de celulares; respeito ao professor -, quando se vê diante de determinados problemas contemporâneos. Obviamente, não se trata aqui da preocupação com um possível esgarçamento das malhas sociais que outrora garantiram relações hierárquicas e que eram fundadas num modelo funcionalista de sociedade. O que se pretende é colocar em questão quais efeitos produzirá (aliás, já está produzindo) a disseminação da racionalidade que rege as soluções para os problemas vivenciados nos espaços escolares, remetendo-os ao poder judiciário.

Lobo (2012) chama a atenção para um fato atual de grande importância: a judicialização do nosso cotidiano. A autora afirma que hoje notamos a multiplicação das atribuições da justiça na sociedade - característica da economia do poder na atualidade -, destacando entre elas questões referentes à mídia, à família, ao trabalho, às mulheres, às crianças, às discriminações de minorias e outras.

Essa espécie de regulamentação jurídica dos comportamentos, entendida como modalidade de governo, parece apontar para uma inversão do que acontecia no século $\mathrm{XIX}$, atribuindo-se, agora, à justiça, funções que eram desempenhadas anteriormente por uma rede não judiciária. Este processo envolve principalmente a redefinição do que pode ou deve ser levado à Justiça, possibilitando o funcionamento dos mecanismos protetores próprios das técnicas de gerenciamento das populações.

Em consonância com o que já foi dito anteriormente acerca da articulação entre os mecanismos de poder disciplinar e os de regulamentação, a autora (Lobo, 2012) afirma a continuidade das técnicas de vigilância e de controle realizadas em espaços disciplinares; porém, diante das ameaças de perda de controle sobre os corpos e as populações, não se hesita em recorrer às leis de modo a garantir a produção de subjetividades que não se desviem do modelo permitido:

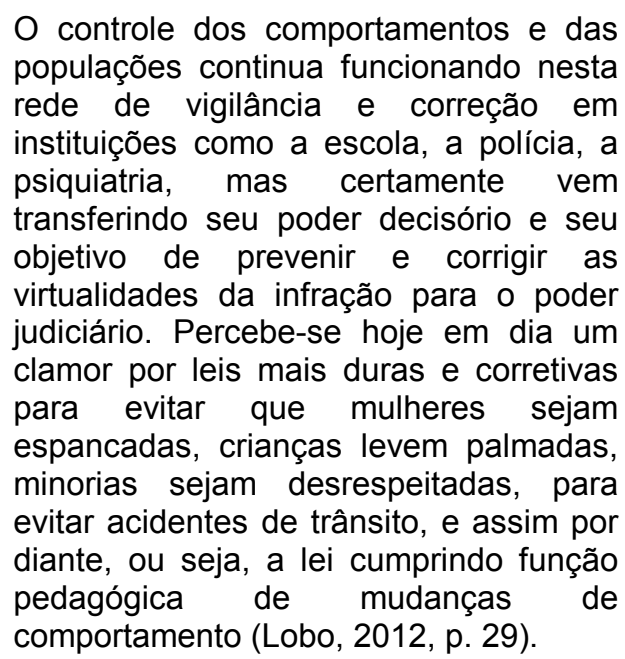

Isto é o que estamos vendo quando, diante dos problemas que the são colocados no cotidiano, a escola recorre às soluções jurídicas e às punições. Chama a atenção a expectativa de que através da definição clara de leis, regulamentos, etc., os comportamentos ou atitudes reprováveis - ou seja, em desconformidade com as leis - possam ser 
punidos e - mais importante ainda -, outros desvios possam ser evitados.

Foucault (2003) já nos havia mostrado que o deslocamento sofrido pela criminologia e penalidade do século XIX levou ao controle "... não tanto sobre se o que fizeram os indivíduos está em conformidade ou não com a lei, mas ao nível do que podem fazer, do que são capazes de fazer, do que estão na iminência de fazer" ( $p$. 85). É isso que vai caracterizar, segundo o filósofo, a noção de periculosidade, ou seja, a noção de que o indivíduo deve ser considerado não pelos seus atos, mas pelas suas virtualidades. Desse modo, pode-se supor por que numa lei como a que pretende exigir dos alunos o respeito ao professor a definição clara e objetiva dos comportamentos ou suas transgressões tem pouca importância. Em rigor, do ponto de vista da noção de periculosidade, o indivíduo não é considerado com base na transgressão propriamente a uma lei, mas em relação às virtualidades de seu comportamento.

Conforme lembra Foucault (2012a) numa das suas inúmeras discussões com os defensores do sistema penal, os problemas da justiça e da punição precisam ser formulados e reformulados sempre, pois é preciso não se esquecer "... o quanto é difícil ser justo e fácil ser injusto" (p. 277); e, chamando a atenção para a necessidade de a sociedade se interrogar sobre a maneira como se deve praticar a justiça, alerta para importância de problematizarmos as relações e as práticas que nos constituem: "Pois uma justiça deve questionar a si própria, assim como uma sociedade só pode viver do trabalho que exerce sobre si mesma e sobre suas instituições" (p. 278).

Os problemas atualmente enfrentados pela escola têm sido tratados como ameaças ao controle que esta pretende exercer sobre os corpos e as populações. Desse modo, as propostas formuladas revelam a dificuldade da escola de se pensar e se interrogar, a fim de encontrar alternativas para lidar com os problemas contemporâneos sem precisar recorrer aos mecanismos de controle disciplinares - aliás, pouco eficientes nos dias de hoje -, nem aos mecanismos legais, baseados na racionalidade jurídica. Estes últimos resultam, muitas vezes, da conclusão equivocada $e$, sobretudo, perigosa, de que precisamos prevenir certos atos através de medidas rígidas de segurança, enquanto, como lembra Foucault (2012b), soluções desse tipo representam “... uma maneira de multiplicar as ocasiões de punir e de designar previamente possíveis delinquentes" (p. 191).

Em outro momento, desta vez não se referindo à periculosidade, mas aos perigos, Foucault (2010) chama a atenção para o fato de que nem todas as coisas são ruins, mas tudo é perigoso - o que nos obriga a identificar quais os principais perigos a enfrentar. Isso coloca uma tarefa fundamental para todos aqueles que lidam com os problemas da educação hoje: problematizar as práticas e as relações instrumentalizadas na escola, cuja amplitude tem se estendido do âmbito do ensino propriamente dito ao das condutas do ponto de vista legal ou jurídico.

Não estaremos lidando de maneira desproporcional com um problema que poderia perfeitamente permanecer circunscrito ao âmbito escolar? Ou seja, a partir da interpretação de certos comportamentos considerados virtualmente delinquentes, desviantes ou, quem sabe, desrespeitosos, não estaremos incorrendo num risco maior?

Talvez por isso, um dos grandes problemas enfrentados por quem tem uma relação mais direta com a escola (alguns educadores, em particular) na atualidade, é a dificuldade de identificar, entre os inúmeros perigos presentes no cotidiano, quais os principais, ou melhor, quais os que precisam ser enfrentados imediatamente. Por essa razão, quando constatamos que a preocupação de alguns em preservar os códigos de conduta e garantir o respeito ao professor resulta na judicialização das questões da escola, inclusive com a definição de ações punitivas para tais atos, precisamos colocar em análise exatamente estes movimentos - sua racionalidade, suas práticas -, porque, conforme observa Foucault (2012b),

... é preciso também interrogar-se sobre
o que merece efetivamente ser punido.
O que pensar das divisões hoje
admitidas entre o que é sancionável pela
lei e o que praticamente não o é? Tantas
preocupações para que os "costumes"
não sejam "ultrajados" nem os "pudores"
pervertidos, e tão poucas para que o
emprego, a saúde, o meio de existência,
a vida não sejam postos em perigo.... (p.
191).

As transformações necessárias para tornar possível a construção de alternativas aos 
problemas da escola poderão acontecer com muito mais chances de acerto se tiverem como protagonistas os próprios sujeitos que a habitam. Através da potencialização de professores, alunos e dos demais agentes institucionais, como autores deste processo, é possível manter a escola como lugar de encontros, de construção de outras possibilidades de formação, enfim, como espaço para a ampliação dos modos de existência. Talvez a escola venha a ser uma nova escola, diferente da que estamos acostumados a ver. Certamente não estará isenta de mecanismos de poder, como, aliás, nenhuma esteve até hoje, mas tampouco precisaremos de mais vigilância, mais controle, mais leis para que funcione.

Ao encerrar este artigo, chamo a atenção para dois aspectos fundamentais: a necessidade de encararmos os problemas surgidos na escola não como ameaças a sua existência, mas como analisadores dos processos instituídos, e de problematizarmos as práticas que pretendem prevenir certas condutas desviantes através de discursos moralizantes e de métodos punitivos. Por fim, destaco um dos perigos que certamente precisaremos enfrentar o quanto antes: a invasão da escola pelos processos que judicializam a vida.

\section{REFERÊNCIAS}

CBN. (2013). Missão aluno. Recuperado em 10 de setembro de 2013, de http://cbn.globoradio.globo.com/colunas/missaoaluno/2013/09/02/CARTAZES-PELA-EDUCACAO-NOSETE-DE-SETEMBRO.htm.

Deleuze, G. (1992). Post-scriptum sobre as sociedades de controle. In G. Deleuze. Conversações (pp. 219-226). Rio de Janeiro: 34.

Dreyfus, H. \& Rabinow, P. (2010). Michel Foucault: uma trajetória filosófica: para além do estruturalismo e da hermenêutica. Rio de Janeiro: Forense Universitária.
Laurindo Filho, L. (2013). As ruas e o vaivém da mídia. Le Monde Diplomatique, 6 (72), 7.

Foucault, M. (1989) Vigiar e punir: história da violência nas prisões. Petrópolis, RJ: Vozes.

Foucault, M. (1999). Em defesa da sociedade. São Paulo: Martins Fontes.

Foucault, M. (2003). A verdade e as formas jurídicas. Rio de Janeiro: Nau / PUC-Rio.

Foucault, M. (2012a). O senhor é perigoso. In M. Barros de Motta (Org.). Ditos e escritos VIII - Segurança, Penalidade e Prisão (pp. 276-278). Rio de Janeiro: Forense Universitária.

Foucault, M. (2012b). Michel Foucault: é preciso repensar tudo, a lei e a prisão. In M. Barros de Motta (Org.). Ditos e escritos VIII - Segurança, Penalidade e Prisão (pp. 189191). Rio de Janeiro: Forense Universitária.

Heckert, A. L. \& Rocha, M. L. (2012). A maquinaria escolar e os processos de regulamentação da vida. Psicologia \& Sociedade; 24(n.spe.), 85-93.

Lobo, L. F. (2012). A expansão dos poderes judiciários. Psicologia \& Sociedade; 24(n. spe.), 25-30.

Lourau, R. (1993). Análise Institucional e Práticas de Pesquisa. Rio de Janeiro: UERJ.

Machado, L. D. (1999). Subjetividades contemporâneas. In Barros, M. E. B. de. (Org.). Psicologia: questões contemporâneas (pp. 211-229). Vitória: EDUFES.

Projeto de lei 267/11 de 2011. (2011). Acrescenta o art. 53-A a Lei n. $^{\circ} 8.069$, de 13 de julho de 1990, que "dispõe sobre o Estatuto da Criança e do Adolescente e dá outras providências", a fim de estabelecer deveres e responsabilidades à criança e ao adolescente estudante. Recuperado em 3 de novembro, 2013, de http://www.camara.gov.br/proposicoesWeb/prop mostrarin tegra;jsessionid=C1F22298DEE6138427A4A928F403599 0.node1 ?codteor $=838075$ \&filename $=P L+267 / 2011$.

Sibilia, P. (2012). Redes ou paredes: a escola em tempos de dispersão. Rio de Janeiro: Contraponto.

Recebido em 20/11/2013 Aceito em 26/09/2014

Luiz Antonio Saléh Amado: mestre em Psicologia Social; doutor em Psicologia Social; professor adjunto da Faculdade de Educação da Baixada Fluminense; professor permanente do Programa de Pós-graduação em Políticas Públicas e Formação Humana da Universidade do Estado do Rio de Janeiro, Brasil. 